\title{
Feasibility of Single Port Laparoscopic Surgery in Patients with Perforated Appendicitis
}

\author{
Byung Seo Choi, M.D., Geon Young Byun, M.D., Seong Bae Hwang, M.D., Sung Ryul Lee, M.D.
}

Department of Surgery, Damsoyu Hospital, Seoul, Korea

Purpose: In recent years, single-port laparoscopic appendectomy (SPLA) has been gaining in popularity and there have been many reports on the results of SPLA. The purpose of this study is to investigate feasibility, safety, and cosmetic satisfaction with SPLA in treatment of perforated appendicitis.

Methods: From September 2012 to March 2015, 227 patients underwent SPLA at Damsoyu hospital. The patients were divided into the simple and gangrenous appendicitis group (the $\mathrm{S} \& \mathrm{G}$ group) and the perforated appendicitis group (the P group). Operation time, hospital stay, drain insertion rate, surgical complication, and cosmetic satisfaction were evaluated.

Results: A total of 227 patients consisted of 32 patients in the P group and 195 patients in the S \& G group. There were no significant differences in the demographic data of the patients. The operation time and hospital stay were significantly longer in the P group ( $p=0.002$ and $p<0.0001$, respectively). The rate of drain insertion was also higher in the $\mathrm{P}$ group $(p=0.0002)$. However, no differences in postoperative complications $(p=0.281)$ and cosmetic satisfaction $(p=0.090)$ were observed between the two groups.

Conclusion: SPLA for perforated appendicitis is a feasible, safe, and cosmetically acceptable procedure. However, longer operation time and hospital stay and higher drain insertion rate should be considered for patients undergoing SPLA for perforated appendicitis.

Keywords: Laparoscopy, Single incision, Appendicitis

This is an Open Access article distributed under the terms of the Creative Commons Attribution Non-Commercial License (http:// creativecommons.org/licenses/by-nc/4.0/) which permits unrestricted non-commercial use, distribution, and reproduction in any medium, provided the original work is properly cited.
Received October 2, 2015

Revised 1st October 26, 2015

2nd October 28, 2015

Accepted November 2, 2015

Corresponding author

Sung Ryul Lee

Department of Surgery, Damsoyu

Hospital, 213, Bongeunsa-ro,

Gangnam-gu, Seoul 06109, Korea

Tel: $+82-2-542-2222$

Fax: +82-2-542-0099

E-mail: Kingsoss@naver.com

\section{INTRODUCTION}

Acute appendicitis is a common disease which requires emergency surgery. Since its first introduction by Semm in 1983, ${ }^{1}$ laparoscopic appendectomy has been conducted more frequently than the open appendectomy. This has been due to numerous advantages of laparoscopic appendectomy, such as less postoperative pain, faster recovery, lower wound complication, and shorter length of hospital stay. ${ }^{2-4}$ As minimal invasive surgical techniques and instruments have gradually developed, the use of single-port laparoscopic appendectomy (SPLA) has become more frequent and numerous studies addressed the advantages and disadvantages of SPLA as compared to conventional laparoscopic appendectomy (CLA), ${ }^{5,6}$ However, SPLA has some technical limits, such as restricted vision and reduced degree of freedom in using laparoscopic instruments. Therefore, this study aims to investigate feasibility, safety, and cosmetic result of SPLA in treating perforated appendicitis, which is a more difficult procedure than SPLA for simple and gangrenous appendicitis. 


\section{MATERIALS AND METHODS}

A retrospective study was conducted for the patients who underwent SPLA for acute appendicitis at Damsoyu hospital from September 2012 to March 2015. Prior to surgery, abdominal ultrasound or computed tomography was performed and the patients with appendiceal abscess requiring interval appendectomy or percutaneous abscess drainage were excluded from the dataset. ${ }^{8}$ The total number of patients amounted to 227 and all were fully informed about the advantages and disadvantages of SPLA. Patient data, including relevant demographic information, were collected from medical records. Outcome variables were operation time, hospital stay, operative complications, drain insertion rate, and cosmetic satisfaction.

In our hospital, three surgeons are responsible for diagnosis and treatment of appendicitis and all of them are trained experts in laparoscopy with previous experience in SPLA. Under general anesthesia, the open incision method was used.
After the umbilicus was pulled out, about $1.5-\mathrm{cm}$ sized single vertical, intraumbilical incision was made. The glove port (Nelis, Bucheon, Korea) with three trocar channels (Fig. 1) was placed into the defect created on the abdominal wall. After pneumoperitoneum was established and a patient was placed in the Trendelenburg and left down position, laparoscopic appendectomy was performed. Conventional $5 \mathrm{~mm}, 30^{\circ}$-angle, rigid laparoscopic camera and instruments were used. After the mesoappendix was divided with monopolar electrocautery, the base of the appendix was ligated with a single application of endo-loop (Sejong Medical, Paju, Korea). To prevent spillage, the base of the appendix was held with a grasper and then resected with a scissor. Because of the wound retractor, a retrieval bag was not required and the appendix was added to one of the fingers of the glove. If the appendix was big, it was removed with a Lap-bag (Sejong Medical, Paju, Korea) to prevent spillage or contamination. If there was an exudate or a pustular discharge in the peritoneal cavity, suction removal was performed instead of irrigation. In cases of severe
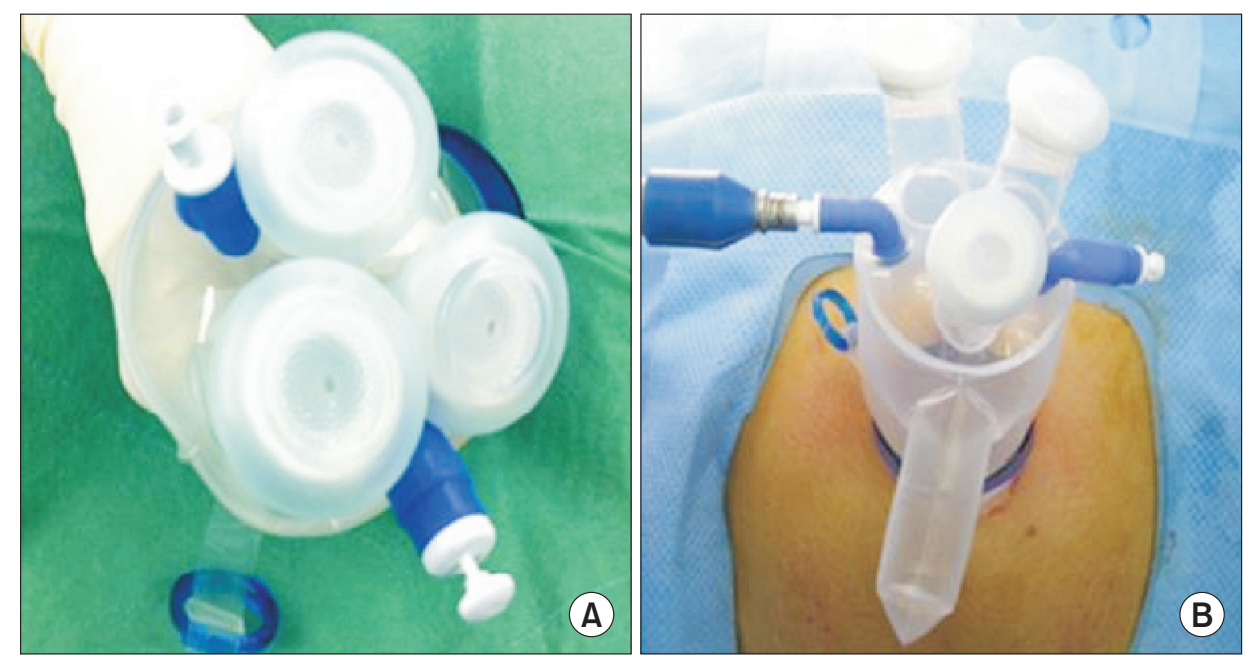

Fig. 1. (A, B) Glove port for single port surgery.
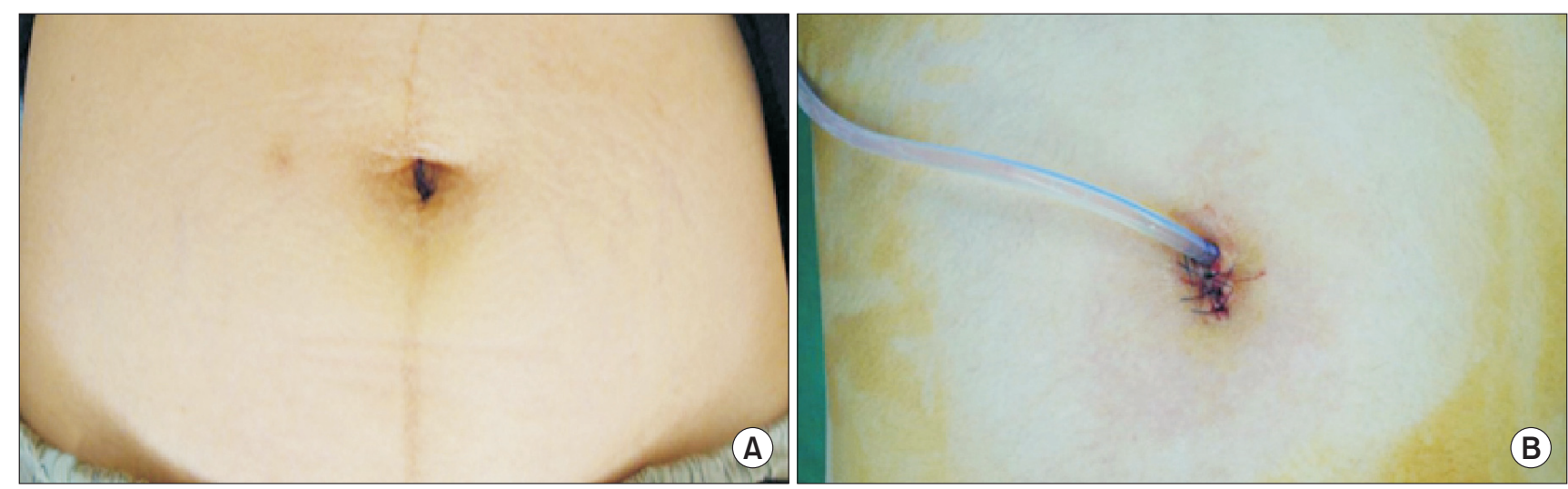

Fig. 2. (A) Postoperative scar after single port surgery (B) Jackson-Pratt drain insertion through umbilical wound. 
intraabdominal contamination, Jackson-Pratt drain (JP drain) was inserted through the umbilical port (Fig. 2). The fascia and peritoneum were closed with Vicryl Plus \#2-0 (Ethicon Inc., Somerville, NJ, USA) and the subcutaneous tissue and the skin were closed with Vicryl Plus \#4-0.

After appendectomy, all patients followed the critical pathway of Damsoyu hospital. Unless they had paralytic ileus or rejected meals due to postoperative nausea, they were allowed to drink water 5 hours after the surgery and, if tolerable, a soft diet was permitted within 2 hours. If there were no problems after oral intake and if no JP drain was observed, the patients could be discharged from the hospital on the same day after the surgery. For the patients with the JP drain, the color of the discharge fluid was checked for serosanguinity and, if the drainage was on decline, the patients were discharged after removing the drain. The time until the JP drain removal was noted and it measured the time period between the postoperative admission to the care unit and the drain removal. After the operation, the surgical bond (Dermabond; Ethicon, Inc., Somerville, NJ) was used for covering the incision and, therefore, wound dressing was usually unnecessary after the discharge. The patients who had the drain removed were discharged after appropriate selfwound care education. In most cases, an outpatient follow-up was unnecessary. Instead of outpatient follow up, telephone interviews 2 and 7 days after the discharge were conducted. If the patients were uncomfortable, they were admitted to the outpatient clinic. The patients' cosmetic satisfaction (with the scores 0 (dissatisfied) to 5 (satisfied)) was also evaluated in a telephone interview on day 7 after the discharge.

Statistical analyses were performed with SPSS ver. 22.0 (IBM
Co., Armonk, NY, USA). Categorical variables were analyzed with the chi-square test (sex) or Fisher's exact test (drain insertion, complication, and past medical history). Continuous variable (age) was compared with two-sample t-test; other nonparametric variables (operation time, hospital stay, BMI, and cosmetic satisfaction score) were tested with MannWhitney U-test. $p$ values below 0.05 were considered to be statistically significant.

\section{RESULTS}

A total of 227 patients were included in the study. The patients were divided into two different groups: the simple and gangrenous appendicitis group (the $\mathrm{S} \& \mathrm{G}$ group, $\mathrm{N}=195$ ) and the perforated appendicitis group (the P group, $N=32$ ). The mean age of the patients was 32.8 years (range, 7 61 years) for the $S \& G$ group and 34.8 years (range, 9 55 years) for the P group. There were 108 males and 87 females in the $\mathrm{S} \& \mathrm{G}$ group and 19 males and 13 females in the $\mathrm{P}$ group. The mean body mass index of the patients was $22.2 \mathrm{~kg} / \mathrm{m}^{2}$ in the $\mathrm{S} \& \mathrm{G}$ group and $22.69 \mathrm{~kg} / \mathrm{m}^{2}$ in the $\mathrm{P}$ group. Including $\mathrm{co}^{-}$ morbidities, all demographic variables described above did not show statistically significant differences between the two groups (Table 1).

Among the operative outcome variables, the $\mathrm{P}$ group had a significantly longer operation time than the $S \& G$ group $(40.5 \pm 20.9$ minutes vs. $23.6 \pm 12.3$ minutes, respectively; $p=$ $0.002)$, a longer hospital stay (1.8 \pm 1.1 days vs. $0.6 \pm 0.6$ days, respectively; $p<0.0001)$, and a higher drain insertion rate $(15.6 \%$ vs. $0.5 \%$, respectively, $p=0.0002$ ). The actual number of the drain insertion cases was 8 out of all 227 patients, 7 of which

Table 1. Demographic results of the simple and gangrenous appendicitis group and the perforated appendicitis group

\begin{tabular}{lccc}
\hline & $\begin{array}{c}\text { S-G group } \\
(\mathbf{n}=195)\end{array}$ & $\begin{array}{c}P \text { group } \\
(\mathbf{n}=32)\end{array}$ & $p$ value \\
\hline Mean age (years) & $32.8 \pm 10.4(12 \sim 61)$ & $34.8 \pm 10.7(5 \sim 55)$ & 0.313 \\
\hline Gender & $108(55.4)$ & $19(59.4)$ & 0.673 \\
Male & $87(44.6)$ & $13(40.6)$ & 0.238 \\
Female & $11(5.6)$ & $4(12.5)$ & \\
Co-morbidities & 8 & 1 & \\
Hypertension & 1 & 2 & \\
Diabetes mellitus & 2 & 0 & 0.459 \\
Asthma & 0 & $22.7 \pm 3.3(17.7 \sim 28.4)$ & \\
Rheumatoid arthritis & $22.2 \pm 3.8(14.8 \sim 35.3)$ & & \\
Body mass index $\left(\mathrm{kg} / \mathrm{m}^{2}\right)$ &
\end{tabular}

Categorical variables are represented as number $(\%)$ and continuous variables as mean \pm standard deviation and ranges. 
Table 2. Postoperative clinical data

\begin{tabular}{lccc}
\hline $\begin{array}{c}\text { S-G group } \\
(\mathbf{n}=195)\end{array}$ & $\begin{array}{c}\text { P group } \\
(\mathbf{n}=32)\end{array}$ & $p$ value \\
\hline Operation time (minute) & $23.6 \pm 12.3(12 \sim 105)$ & $40.5 \pm 20.9(17 \sim 80)$ & 0.002 \\
\hline Hospital stay (day) & $0.6 \pm 0.6(0 \sim 4)$ & $1.8 \pm 1.1(0 \sim 6)$ & $<0.0001$ \\
\hline Drain insertion & $1(0.5)$ & $5(15.6)$ & 0.0002 \\
Complication & $8(4.1)$ & $2(6.3)$ & 0.281 \\
Wound infection & 8 & 1 & \\
Ileus & 0 & 1 & 0.090 \\
\hline Cosmetic score & $4.89 \pm 0.38$ & $4.72 \pm 0.57$ & \\
\hline
\end{tabular}

Categorical variables are represented as number $(\%)$ and continuous variables as mean \pm standard deviation and ranges.

were from the $\mathrm{P}$ group. The time until the drain removal was on average 44.4 hours for the P group and 71 hours for the only relevant case in the $S \& G$ group; this difference was not statistically significant $(p=0.105)$. Among a total of 227 surgeries, only 10 cases of complications were observed. These included no major complication and 9 of them were cases of wound infection. There was one case of postoperative ileus. The differences in the complication rate between the two groups were not statistically meaningful. There was no conversion to open appendectomy or CLA during SPLA. The patients' mean cosmetic satisfaction score was $4.89 \pm 0.38$ for the $S \& G$ group and $4.72 \pm 0.57$ for the P group $(p=0.090)$. In the whole patient, the mean cosmetic satisfaction score of the patients was $4.86 \pm 0.42$. The operative outcome results are summarized in Table 2.

\section{DISCUSSION}

Single-port laparoscopic appendectomy has been gaining in popularity and numerous reports on the results of SPLA are available. Gill et al. ${ }^{5}$ review 9 studies that report no significant differences in operation time, length of hospital stay, pain score, conversion rate, and complication rate between SPLA and CLA. However, SPLA has several limitations, such as restricted degree of freedom of the laparoscopic instruments and the proximity of the instrument to each other, both of which increase the complexity and technical challenges of the operation. Usually, the surgery for perforated appendicitis is more difficult than that for simple and gangrenous appendicitis and, sometimes, there are cases requiring conversion to open surgery or CLA. ${ }^{9}$ There have been several reports about the results of laparoscopic appendectomy for complicated appendicitis. Compared to the open appendectomy, a lower surgical site infection rate, a comparable intra-abdominal infection rate, and a shorter hospital stay were observed in the CLA for complicated appendicitis. ${ }^{10-13}$ The results of another study investigating the use of SPLA for complicated appendicitis suggest that, as compared to CLA, SPLA leads to no increase in hospital stay and operation time and results in no difference in complications, such as wound infection. ${ }^{14}$

In the present study, the P group had a longer operation time and hospital stay as well as a higher drain insertion rate than the $S \& G$ group; however, there was no significant difference in complications between the two groups. Most of the complications were wound infection and major complications were not observed in this study. Furthermore, there was neither a conversion to open appendectomy, nor an additional port insertion in both groups. Although operation time and hospital stay were higher in the P group as compared to the $S \& G$ group, the $P$ group in the present study showed a shorter operation time $(40.5 \pm 20.9 \mathrm{~min})$, a shorter postoperative hospital stay (1.8 \pm 1.1 days), and a comparable complication rate, when compared to the results of previous studies. ${ }^{15-19}$

For the cases with the JP drain insertion, the time until the drain removal did not show any statistically significant difference between the two groups. One such case in the $S \& G$ group was accompanied with diverticulitis of the right colon and the patient stayed at the hospital for 4 days, which naturally lengthened the time until the drain removal to 71 hours. One specific case should not be taken as representative of the $S \& G$ group and cannot be meaningfully compared to other drain insertion cases in the $\mathrm{P}$ group.

There has been a controversy about the timing of oral intake after surgery. Traditional management begins with clinical monitoring for the return of bowel function, including bowel sound and passage of flatus. In our institution, if a patient can tolerate, a soft diet was provided to the patient within 7 hours post-surgery without checking for bowel movement. Oral intake was postponed for one patient due to postoperative ileus in the P group; this patient was discharged after 36 hours 
of conservative treatment. While there were two cases of oral intake delay in the $S \& G$ group, both patients voluntarily refused diet due to nausea that emerged as a side effect of patient controlled anesthesia (PCA). The patients' condition improved after discontinuing PCA and both were able to have diet. Except for these delays in oral intake, complications were not observed once the soft diet was administered, even when the time of first feeding was earlier than in other institutions. ${ }^{20,21}$ Several reports are available on the benefits of early feeding, such as the reduction of infectious complication and the promotion of wound healing. ${ }^{20,21}$ Another study reports a reduction of postoperative hospital stay in the case of early feeding after open appendectomy. ${ }^{22}$

In our institution, , if there was no problem after feeding, the patients were discharged on the day of surgery. The mean postoperative hospital stay in the $\mathrm{S} \& \mathrm{G}$ group and the $\mathrm{P}$ group amounted to $0.6 \pm 0.6$ days and $1.8 \pm 1.1$ days, respectively. Lee et al. ${ }^{23}$ report that an early discharge (within 48 hours) of patients with uncomplicated appendicitis is safe. In our study, no complications associated with early discharge were observed.

Lee et al. ${ }^{24}$ report that cosmetic satisfaction score to not significantly differ between CLA and SPLA. In our study, the cosmetic satisfaction scores showed comparable results as well. It is worth noting that the cosmetic results were similar even when the P group had more cases with the drain insertion through an umbilical incision. In addition, most patients were satisfied with the cosmetic results of single-port appendectomy.

Our study is not without limitations. First, the JP drain insertion was determined by clinical judgment of the surgeon without objective guidelines on the severity of intraperitoneal contamination. This arbitration might have influenced the results. Second, in our institution, we monitored for possible complications through phone interviews at day 2 and day 7 post-surgery. If the patients were experiencing problems, such as fever, nausea, vomiting, and abdominal pain, they were admitted to the outpatient clinic; however, self-reported conditions may have introduced error to the data. Third, this study is a retrospective study of a relatively small number of patients. Therefore, further multicenter, prospective, randomized trials would be helpful to verify safety and feasibility of SPLA for perforated appendicitis.

Despite the limitations overviewed above, our study convincingly demonstrates that SPLA is a technically feasible, safe, and cosmetically acceptable procedure for perforated appendicitis. This said, one should however use caution, since there may be problems related to the increase in postoperative hospital stay and operation time. When these downsides are permissible, SPLA can be accepted as one of the surgical treatment options for perforated appendicitis.

\section{REFERENCES}

1) Semm K. Endoscopic appendectomy. Endoscopy 1983;15:59-64.

2) Chung RS, Rowland DY, Li P, Diaz J. A meta-analysis of randomized controlled trials of laparoscopic versus conventional appendectomy. Am J Surg 1999;177:250-256.

3) Golub R, Siddiqui F, Pohl D. Laparoscopic versus open appendectomy: a metaanalysis. J Am Coll Surg 1998;186:545-553.

4) Nguyen NT, Zainabadi K, Mavandadi S, et al. Trends in utilization and outcomes of laparoscopic versus open appendectomy. Am J Surg 2004;188:813-820.

5) Gill RS, Shi X, Al-Adra DP, Birch DW, Karmali S. Singleincision appendectomy is comparable to conventional laparoscopic appendectomy: a systematic review and pooled analysis. Surg Laparosc Endosc Percutan Tech 2012;22:319-327.

6) St Peter SD, Adibe OO, Juang D, et al. Single incision versus standard 3-port laparoscopic appendectomy: a prospective randomized trial. Ann Surg 2011;254:586-590.

7) Jeong SY. Single-incision laparoscopic appendectomy. J Korean Soc Coloproctol 2012;28:282-283.

8) Brown CV, Abrishami M, Muller M, Velmahos GC. Appendiceal abscess: immediate operation or percutaneous drainage? Am Surg 2003;69:829-832.

9) Antonacci N, Ricci C, Taffurelli G, et al. Laparoscopic appendectomy: Which factors are predictors of conversion? A high-volume prospective cohort study. Int J Surg 2015.

10) Kim JM, Lee SR, Kim HO. Comparison of clinical outcomes after laparoscopic and open appendectomy for complicated appendicitis. Journal of minimally invasive surgery 2013;16:98-103.

11) Markides G, Subar D, Riyad K. Laparoscopic versus open appendectomy in adults with complicated appendicitis: systematic review and meta-analysis. World J Surg 2010;34:2026-2040.

12) Katsuno G, Nagakari K, Yoshikawa S, Sugiyama K, Fukunaga M. Laparoscopic appendectomy for complicated appendicitis: a comparison with open appendectomy. World J Surg 2009;33:208214.

13) Dimitriou I, Reckmann B, Nephuth O, Betzler M. Single institution's experience in laparoscopic appendectomy as a suitable therapy for complicated appendicitis. Langenbecks Arch Surg 2013;398:147-152.

14) Kang KC, Lee SY, Kang DB, et al. Application of single incision laparoscopic surgery for appendectomies in patients with complicated appendicitis. J Korean Soc Coloproctol 2010;26:388-394.

15) Baik SM, Hong KS, Kim YI. A comparison of transumbilical single-port laparoscopic appendectomy and conventional threeport laparoscopic appendectomy: from the diagnosis to the hospital cost. J Korean Surg Soc 2013;85:68-74.

16) Lee JS, Choi YI, Lim SH, Hong TH. Transumbilical single port 
laparoscopic appendectomy using basic equipment: a comparison with the three ports method. J Korean Surg Soc 2012;83:212-217.

17) Kim H, Jung IM, Yun KW, et al. Early outcome of the Korean Diagnosis-Related Groups payment system for appendectomy. Ann Surg Treat Res 2015;88:126-132.

18) Vilallonga R, Barbaros U, Nada A, et al. Single-port transumbilical laparoscopic appendectomy: a preliminary multicentric comparative study in 87 patients with acute appendicitis. Minim Invasive Surg 2012;2012:492409.

19) Lee JA, Sung KY, Lee JH, Lee dS. Laparoscopic appendectomy with a single incision in a single institute. J Korean Soc Coloproctol 2010;26:260-264.

20) Warren J, Bhalla V, Cresci G. Postoperative diet advancement: surgical dogma vs. evidence-based medicine. Nutr Clin Pract 2011;26:115-125.
21) Lee HS, Shim H, Jang JY, Lee H, Lee JG. Early feeding is feasible after emergency gastrointestinal surgery. Yonsei Med J 2014;55:395-400.

22) Kuzma J. Randomized clinical trial to compare the length of hospital stay and morbidity for early feeding with opioid-sparing analgesia versus traditional care after open appendectomy. Clin Nutr 2008;27:694-699.

23) Lee JM, Jang JY, Lee SH, Shim H, Lee JG. Feasibility of the short hospital stays after laparoscopic appendectomy for uncomplicated appendicitis. Yonsei Med J 2014;55:1606-1610.

24) Lee WS, Choi ST, Lee JN, et al. Single-port laparoscopic appendectomy versus conventional laparoscopic appendectomy: a prospective randomized controlled study. Ann Surg 2013;257:214218. 